\title{
Editorial: Mixotrophy in Protists: From Model Systems to Mathematical Models
}

\author{
Matthew D. Johnson ${ }^{1 *}$ and Holly V. Moeller ${ }^{2}$ \\ ${ }^{1}$ Biology Department, Woods Hole Oceanographic Institution, Woods Hole, MA, United States, ${ }^{2}$ Ecology, Evolution \& Marine \\ Biology, University of California, Santa Barbara, Santa Barbara, CA, United States
}

Keywords: mixotrophy, protists, marine microbial ecology, plankton ecology and pelagic food webs, Ocean biochemistry

\section{Editorial on the Research Topic}

\section{Mixotrophy in Protists: From Model Systems to Mathematical Models}

\section{OPEN ACCESS}

Edited and reviewed by: Angel Borja

Centro Tecnológico Experto en Innovación Marina y Alimentaria (AZTI), Spain

*Correspondence: Matthew D. Johnson mattjohnson@whoi.edu

Specialty section: This article was submitted to Marine Ecosystem Ecology, a section of the journal

Frontiers in Marine Science

Received: 19 November 2018 Accepted: 04 December 2018 Published: 18 December 2018

Citation: Johnson MD and Moeller HV (2018) Editorial: Mixotrophy in Protists: From Model Systems to Mathematical Models. Front. Mar. Sci. 5:490. doi: 10.3389/fmars.2018.00490
Mixotrophy in marine protists is now recognized as a fundamentally important mechanism for acquiring energy or limiting nutrients. This move to center stage follows decades of research establishing that mixotrophy occurs broadly across the eukaryotic tree of life (Selosse et al., 2016) and is more commonplace in aquatic ecosystems than previously thought (Worden et al., 2015). Its ubiquity among microbial eukaryotes in sunlit oligotrophic oceans, and its important roles in coastal temperate and polar ecosystems, has propelled a reevaluation of microbial food web trophic dynamics. Changes in how the broader oceanographic community perceives the role of mixotrophy is evident in the growing interest by theoretical and mathematical ecologists in modeling these phenomena.

The prevalence of mixotrophs among most protist lineages is not surprising, considering that phagotrophy is an ancestral trait in eukaryotes and that most major lineages have members that have acquired stable plastids (Raven, 1997). This metabolic duality can be seen in the ebb and flow of photosynthetic and phagotrophic traits within lineages, and is most vividly reflected within the dinoflagellates (Saldarriaga et al., 2001). Rarely are heterotrophy and phototrophy balanced even within a species, but rather seem to function in a tug of war for cellular resources (Skovgaard, 1996; Adolf et al., 2006; Flynn and Mitra, 2009). Mixotrophs can be broadly categorized as being constitutive (CM), and possessing a stable plastid, or non-constitutive (NCM) and lacking a plastid (Mitra et al., 2016). The NCM are also referred to as acquired phototrophs, since they host endosymbiotic algae or steal their plastids. Both CMs and NCMs practice photosynthesis and phagotrophy simultaneously to fulfill the energetic and nutritional requirements.

While cellular and ecosystem drivers and the physiological role of mixotrophy are well understood for some protists, major gaps remain in our understanding of the broader biogeochemical and trophic implications of mixotrophy. The growing emphasis of mixotrophy in community and ecosystem ecology is helping to bridge this divide and to better focus research efforts. In this Research Topic, Lin et al. use a dynamic mathematical model to illustrate the effects of temperature and nutrients on autotrophic and mixotrophic growth in the harmful alga Karlodinium veneficum. This research suggests that in a warming climate, both the occurrence of mixotrophy and the availability of suitable prey will likely increase for this harmful algal bloom species. 
These findings support the conclusions of Wilken et al. (2013), who found that a warming climate would select for more mixotrophic organisms due to their nutritional flexibility in conditions that will likely result in greater respiration rates and lower nutrient availability.

In a review of mixotrophy in polar seas, Stoecker and Lavrentyev provide a strong case for mixotrophic protists dominating an alternative food web during much of the year that includes mixotrophic flagellates and oligotrich ciliates. Mixotrophic oligotrichs, feeding on mixotrophic flagellates, represent the majority of community chlorophyll within the mixed layer during summer in the Arctic, and provide an important link to mesozooplankton. Stoecker and Lavrentyev highlight the pivotal role of mixotrophs in Arctic food webs, and outline future directions to investigate mixotrophic contributions to community and ecosystem dynamics through empirical research and modeling.

Despite a rich history of research on the physiological ecology of mixotrophs, we still lack fundamental trait based knowledge for many protist groups. This is particularly true of most of Radiolaria and Foraminifera taxa, which are generally not possible to culture and can be difficult to work with due to their delicate structures. Villar et al. reveal that under thermal stress, dinoflagellate symbionts of Collozoum pelagicum (Retaria) undergo a bleaching-like response that may involve activation of a lysogenic virus. While numerous studies have documented the role of thermal stress in cnidarians, this is the first such study for radiolarians. In another study of a NCM, Gomes et al. show that feeding by the dinoflagellate Noctiluca scintillans does not enhance photophysiology of their symbionts when nutrients are not limiting, and that the dinoflagellate is able to fine-tune intracellular nutrient levels when feeding. Finally, McManus et al. found that while the NCM ciliate Strombidium rassoulzadegani displays some flexibility in the types of phytoplankton from which it could steal plastids, it was unable to do so with 6 of the algal prey species investigated, suggesting some degree of variability in prey compatibility and/or selectivity by the ciliate.

Two studies employed state-of-the-art approaches to gain insights into cellular processes in mixotrophs. McKie-Krisberg et al. used transcriptomics to identify genes involved in phagotrophy within Micromonas polaris and Pyramimonas tychotreta, but found little difference in expression levels of these genes under conditions that selected for predominantly phototrophic or phagotrophic metabolism. Carpenter et al. used nanometer-scale secondary ion mass spectrometry (NanoSIMS) to quantify the role of phagotrophy among $P$. parvum cells in

\section{REFERENCES}

Adolf, J. E., Stoecker, D. K., and Harding, L. W. (2006). The balance of autotrophy and heterotrophy during mixotrophic growth of Karlodinium micrum (Dinophyceae). J. Plankton Res. 28, 737-751. doi: 10.1093/plankt/f bl007

Flynn, K. J., and Mitra, A. (2009). Building the "perfect beast": modelling mixotrophic plankton. J. Plankton Res. 31, 965-992. doi: 10.1093/plankt/f bp044 acquiring $\mathrm{C}$ and $\mathrm{N}$. They discovered that $P$. parvum was feeding mainly to acquire $\mathrm{N}$, but that a large degree of variation occurs between individual cells in their assimilation of $\mathrm{N}$. These studies provided novel insights into genomic and metabolic processes within mixotrophs, and illustrate the need for basic research to understand how mixotrophs function.

Finally, several studies in this Research Topic focus on identifying and quantifying in situ interactions between mixotrophs and their prey using a variety of approaches. In situ dynamics of prey selection by mixotrophs remains largely unstudied. Johnson et al. focused on the trophic role of cryptophyte algae in Chesapeake Bay, finding high grazing rates and selective grazing by certain protist predators among cryptophyte species. They demonstrated that in situ grazing helps to shape community cryptophyte diversity by using a combination of molecular approaches and traditional dilution experiments. Lee and Park used single cell approaches to sequence ingested prey of the harmful benthic dinoflagellate Ostreopsis in coastal Korean waters, revealing that it ingests gametes of Rhodophyte macroalgae. Gast et al. studied the contribution of CMs to bacterivory in the Ross Sea during spring and summer, finding that mixotrophs were less abundant than heterotrophic flagellates, but had higher per capita ingestion rates of bacterial prey and were most important during spring. Using bromodeoxyuridine-labeled bacteria as food and immunoprecipitation of labeled DNA, they were also able to identify potential mixotrophs in these samples.

The papers in this Research Topic provide a small sampling of current mixotrophy research and a window into the complex and fascinating interactions within marine microbial food webs. With the growing interest in mixotrophy research and an emphasis on contextualizing this research within theoretical and ecological frameworks, we are entering a period of quickening discoveries and progress in understanding the role of mixotrophy in marine ecosystems.

\section{AUTHOR CONTRIBUTIONS}

All authors listed have made a substantial, direct and intellectual contribution to the work, and approved it for publication.

\section{ACKNOWLEDGMENTS}

MJ thanks the National Science Foundation (OCE 1436169) for providing support for this research. 
losses and replacements. J. Mol. Evol. 53, 204-213. doi: 10.1007/s0023900 10210

Selosse, M. A., Charpin, M., and Not, F. (2016). Mixotrophy everywhere on land and in water: the grand écart hypothesis. Ecol. Lett. 20, 246-263. doi: 10.1111/ele.12714

Skovgaard, A. (1996). Mixotrophy in Fragilidium subglobosum (Dinophyceae): growth and grazing responses as functions of light intensity. Mar. Ecol. Prog. Ser. 143, 247-253. doi: 10.3354/meps143247

Wilken, S., Huisman, J., Naus-Wiezer, S., and Donk, E. (2013). Mixotrophic organisms become more heterotrophic with rising temperature. Ecol. Lett. 16, 225-233. doi: 10.1111/ele.12033

Worden, A. Z., Follows, M. J., Giovannoni, S. J., Wilken, S., Zimmerman, A. E., and Keeling, P. J. (2015). Rethinking the marine carbon cycle: factoring in the multifarious lifestyles of microbes. Science 347:1257594. doi: $10.1126 /$ science. 1257594

Conflict of Interest Statement: The authors declare that the research was conducted in the absence of any commercial or financial relationships that could be construed as a potential conflict of interest.

Copyright $\odot 2018$ Johnson and Moeller. This is an open-access article distributed under the terms of the Creative Commons Attribution License (CC BY). The use, distribution or reproduction in other forums is permitted, provided the original author(s) and the copyright owner(s) are credited and that the original publication in this journal is cited, in accordance with accepted academic practice. No use, distribution or reproduction is permitted which does not comply with these terms. 